\title{
Patient Flow Analysis in General Hospitals: How Clinical Disciplines Affect Outpatient Wait Times
}

\author{
Afsoon Aeenparast ${ }^{1}$, Faranak Farzadi ${ }^{1}$, Farzaneh Maftoon ${ }^{1}$, Hossein Yahyazadeh ${ }^{2 *}$ \\ ${ }^{1}$ Health Metrics Research Center, Iranian Institute for Health Sciences Research, ACECR, Iran \\ ${ }^{2}$ Clinical Cancer Research Center, Milad General Hospital, Tehran, Iran
}

*Corresponding Author: Hosein Yahyazadeh, M.D., Clinical Cancer Research Center, Milad Hospital, Hemmat Exp. Way, Tehran, Iran. Tel: +98-2188621026, Email: hyahyazadeh@gmail.com

Received July 9, 2019; Accepted November 7, 2019; Online Published December 15, 2019

\begin{abstract}
Background: Overcrowding is an important problem for outpatient services in healthcare facilities. Patient flow analysis (PFA) is a useful method for identifying inefficiencies in and facilitating patient flow.

Objective: PFA was used to estimate patient wait time and determine how different clinical disciplines impact wait times in the studied hospital.

Methods: This cross-sectional study investigated a study population comprised of outpatients who referred to clinics at a general hospital in Tehran, Iran. A total of 3836 samples were selected from different stations. Nonrandomized quota sampling was used, and data was gathered using workflow checklists, the content validity of which was proven by experts and hospital authorities. SPSS statistical software was used for data analysis.

Results: Total patient stay in the outpatient setting was an estimated 77 minutes (without considering para-clinic units and pharmacy). More than $90 \%$ of this time was spent waiting. The wait time of patients at the clinic was greater than that ather stations, and it was less at the cash station than at other stations. Wait times varied at different clinics $(P$ value $<0.001)$ and were correlated with physician delay $(P$ value $<0.001)$.

Conclusion: The most important result of using PFA in the outpatient setting was managing wait times. This study indicated that a considerable amount of a patient's total stay in the system was related to waiting for physical examinations. This suggests that the first priority in improving the system should be managing patient wait times for physical examinations.

Keywords: Outpatient Clinics, Hospital, Health Services Accessibility, Time and Motion Studies
\end{abstract}

\section{Background}

Healthcare systems have encountered different challenges in recent years. The main cause of these challenges is the increasing demand for health services along with limited and expensive resources in this domain. ${ }^{1,2}$

Overcrowding of healthcare facilities results from an imbalance between demand and supply. ${ }^{3,4}$ It is an important problem in outpatient facilities where timely access and fast and easy throughput are key performance measures. ${ }^{5,6}$

Overcrowding and inefficient patient flow in healthcare facilities not only affect quality and timeliness of services, but also affect patient satisfaction. ${ }^{2}$

Patient flow analysis (PFA) is a useful tool for identifying patient flow inefficiencies. It also reflects how quick and efficient hospitals are in providing healthcare services, shows possible bottlenecks, and is an evidence-based tool for managing patient flow. The medical community has emphasized the importance of patient flow management by acknowledging it. ${ }^{7,8}$
There is evidence of the application of PFA in healthcare facilities. The main uses of patient flow are for estimating wait time and visit time, ${ }^{2,9,10}$ identifying bottlenecks in service providing processes, ${ }^{11,12}$ optimizing schedules, ${ }^{13,14}$ and planning for future reorganization and resource allocation. ${ }^{8,15-17}$

Studies have focused on a large variety of hospital departments, such as outpatient departments and clinics, emergency departments, inpatient wards, surgical units, and also diagnostic and paraclinic departments. ${ }^{18}$

Results of studies have indicated that PFA was useful in controlling patient wait times and throughput in the system. ${ }^{19,20}$ They also showed that PFA was successful in increasing the rate of accepted patients in a defined period by decreasing repeated visits to clinics. PFA was described as a simple and cost-effective method in assessing the function of outpatient facilities. ${ }^{21,22}$

It seems that improvements in operation research methods and software in recent decades have pushed

Copyright $\odot 2019$ The Author(s). This is an open-access article distributed under the terms of the Creative Commons Attribution License (http:// creativecommons.org/licenses/by/4.0), which permits unrestricted use, distribution, and reproduction in any medium, provided the original work is properly cited. 
research toward decision-making using PFA. Providing an exact and comprehensive picture of the present situation has an important role in managing processes and improving the efficiency and effectiveness of services. ${ }^{23,24}$

The importance of this approach is twofold in systems that suffer from a scarcity of resources and increasing demand, such as the hospital in the current study.

The studied hospital was a large general non-educational hospital in Tehran, Iran. This center provides not only comprehensive inpatient and outpatient services, but also a wide range of paraclinic and diagnostic services mainly to the population under coverage of the social security insurance in the country. The comprehensiveness of services on one hand and decreased out-of-pocket payments by providing insurance coverage on the other has increased the demand for services in this center. Improving patient flow at this center would enable more patients to be treated and access to services to be increased.

\section{Objective}

This study aimed to analyze patient flow in hospital clinics for estimating patient wait time and assessing the impact of different clinic disciplines on the wait time in the studied hospital.

\section{Methods}

This cross-sectional study was conducted in 2013. The study population was outpatients referring to clinics of a general hospital in Tehran, Iran. The large variety of outpatient services is provided in this hospital. Patients are admitted in hospital clinics as either scheduled or walkin patients. The minimum sample size in each station was estimated to be 250 cases by considering $\alpha=0.05, \beta=80 \%$, $\delta=5.12$ minutes, and $\mathrm{d}=1$ minute. ${ }^{25} \mathrm{~A}$ total of 4336 samples was selected from different stations as follows: 336 from the admissions department, 250 from the cash department, 250 from follow-up appointments, and 3500 from 14 specialty clinics (internal medicine, general surgery, obstetrics and gynecology, cardiology, infectious disease, orthopedic, urology, ear nose and throat, dermatology, ophthalmology, psychology, neurology, neurosurgery, and anesthesiology). Nonrandomized quota sampling was performed in different stations of the service delivery process. Samples were selected independently from different clinics on different days of the week. Sampling was continued until the sample size was completed. The inclusion criteria comprised consent to participate in the study and receiving outpatient services at the hospital clinics.

Before data was gathered, the aim and process of the study were explained to the patients. Only those patients who agreed to participate were included in the study. The identity of the patients was kept confidential. A checklist made by the researchers, who considered the study aim and outpatient workflow at the setting, was used to record patient entrance and exit times at each station. The content validity of the checklist was proven by experts and hospital authorized. Data was gathered by five trained questioners who were familiar with the hospital and its workflow. SPSS statistical software was used for data analysis. Descriptive analysis was used to estimate central and dispersion indices, the Kolmogorov-Smirnov test was used to test the normality of the intended variables, Kruskal-Wallis and Mann-Whitney nonparametric tests were used to compare means, and the Spearman coefficient was used to analyze the correlation.

\section{Results}

This study evaluated 336, 250 259, and 3500 samples from the admissions department, cash station, followup appointments, and hospital clinics, respectively. The patient flow of outpatients (Figure 1) was analyzed.

The results indicated that patient wait times were higher

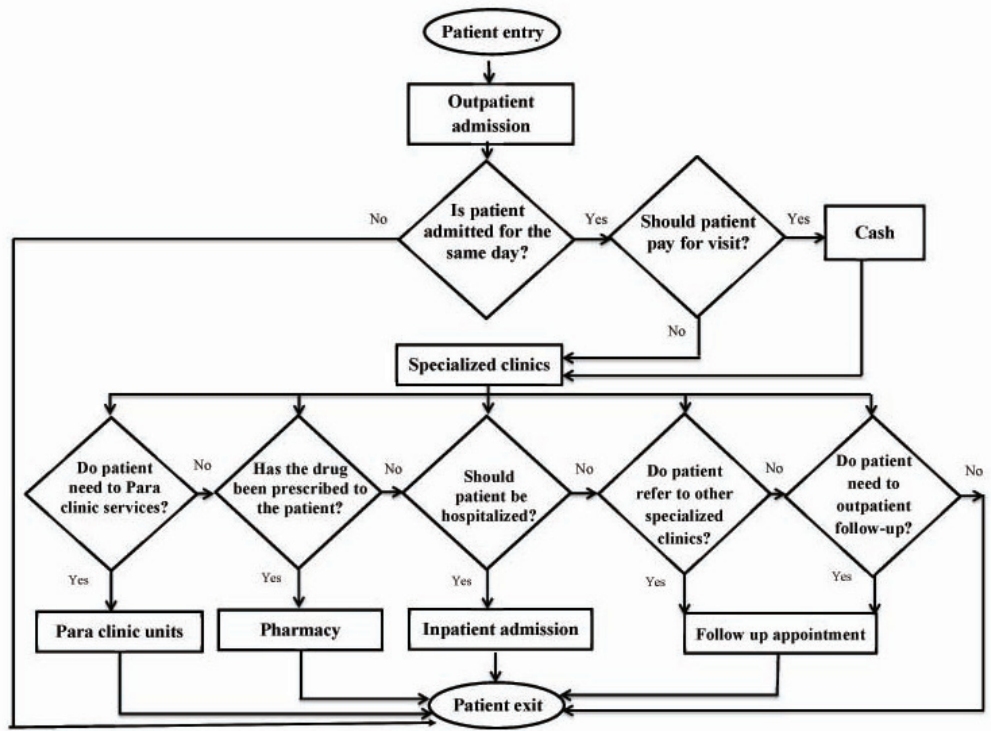

Figure 1. Patient Flow Analysis in Studied Hospital. 
at the clinics and lower at the cash station than at any other stations. The descriptive statistics of patient wait times and service times are presented in Table 1.

Data analysis indicated that patients who referred to all stations, including admissions, cash, clinics, and follow-up appointments, waited 70.2 minutes to receive 6.8 minutes of services. Thus, total time for patient attendance was estimated to be 77 minutes (without considering paraclinic units and pharmacy). It can be concluded that more than $91 \%$ of patient attendance time was spent waiting for services, and less than $9 \%$ was spent receiving services. Therefore, the waiting time is a considerable challenge in the studied center (Figure 2).

The examination room was responsible for about $82.2 \%$ of total patient wait time and $55.9 \%$ of total service time (Table 1).

More investigation into outpatient wait times for doctor visits in different specialty clinics indicated that this variable was not the same at all clinics $(P<0.001)$. Patients experienced the lowest wait time at the anesthesia clinic and the highest wait time for the surgery clinic. The complete information of waiting time in specialty clinics is presented in Table 2.

In the current study, physician delay times in different clinics were also assessed. The official start time of the clinics was 8:00 AM. Physician delay was measured from this time as a criterion. Statistical analysis indicated that this variable differed significantly among clinics. Detailed information is provided in Table 3.

Analyzing the correlation of outpatient wait times and physician delay times indicated that these variables had a significant and positive relationship $(P<0.001$, Spearman correlation $=0.37)$.

\section{Discussion}

Wait times for outpatients and the management thereof is a major challenge to providing outpatient services, especially in large centers and hospitals. ${ }^{26}$

Studying patient flow in the system will help identify the current status of the system and its bottlenecks and will play an important role in managing the delivery process and, ultimately, reducing wait times for patients. ${ }^{1}$

Patient flow assessment results from the studied hospital indicated that more than $91 \%$ of a patient's total stay in the

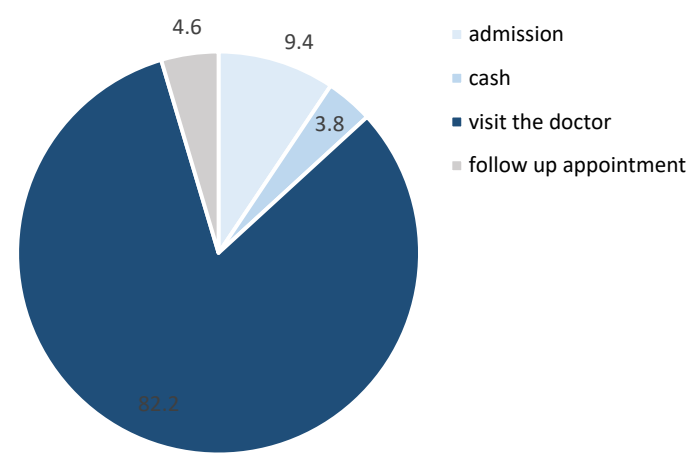

Figure 2. Wait Times at Different Service Providing Stations.

Table 2. Outpatient Wait Times (in Minutes) at Different Specialty Clinics in the Studied Center ${ }^{a}$

\begin{tabular}{lccc}
\hline Specialty Clinic & Mean & Standard Deviation & Median \\
\hline Ear, nose, and throat & 102.7 & 68.2 & 91.0 \\
Orthopedic & 68.5 & 40.2 & 72.0 \\
Urology & 70.6 & 59.0 & 58.0 \\
\hline Psychology & 70.6 & 49.9 & 81.0 \\
Anesthesia & 36.8 & 25.4 & 30.0 \\
\hline Dermatology & 76.5 & 58.7 & 67.0 \\
\hline Surgery & 103.3 & 47.3 & 103.0 \\
\hline Ophthalmology & 69.0 & 45.3 & 63.0 \\
\hline Cardiovascular & 67.8 & 43.9 & 59.0 \\
\hline Internal disease & 46.6 & 49.9 & 64.0 \\
\hline Infectious disease & 55.4 & 37.5 & 51.0 \\
\hline Obstetrics and gynecology & 57.1 & 43.8 & 60.0 \\
\hline Neurosurgery & 102.8 & 66.6 & 102.0 \\
\hline Neurology & 80.7 & 62.9 & 67.0 \\
\hline Total & 57.7 & 54.9 & 65.0 \\
\hline
\end{tabular}

a $P$ value $<0.001$

system was related to wait time, and more than $82 \%$ of total wait time was for physical examinations. Mohebbifar et al indicated that $61.72 \%$ of total wait time was related to the pre-examination stage, and Pandit showed that the average wait time for a consultation was about 40 minutes, which is longer than other wait times in the process of providing outpatient services. This suggests that the first priority of actions to reduce wait times is to manage patient wait times for a physician examination..$^{8,27}$

Table 1. Descriptive Statistics of Waiting Times and Service Times at Different Service Providing Stations

\begin{tabular}{|c|c|c|c|c|c|c|c|}
\hline Variable & Station & No. of Samples & Mean (min) & Median (min) & Standard Deviation (min) & Minimum (min) & Maximum (min) \\
\hline \multirow{4}{*}{ Wait time } & Admissions & 336 & 6.6 & 4.0 & 7.6 & 0.0 & 37.0 \\
\hline & Cash & 250 & 2.7 & 2.0 & 2.9 & 0.0 & 14.0 \\
\hline & Clinics & 3500 & 57.7 & 65.0 & 54.9 & 0.0 & 297.0 \\
\hline & Follow-up appointment & 259 & 3.2 & 1.0 & 4.8 & 0.0 & 19.0 \\
\hline \multirow{4}{*}{$\begin{array}{l}\text { Service } \\
\text { time }\end{array}$} & Admissions & 336 & 0.4 & 0.0 & 7.0 & 0.0 & 3.0 \\
\hline & Cash & 250 & 1.4 & 1.0 & 0.6 & 0.0 & 4.0 \\
\hline & Clinics & 3500 & 3.8 & 3.0 & 2.0 & 0.0 & 20.0 \\
\hline & Follow-up appointment & 259 & 1.2 & 1.0 & 0.5 & 0.0 & 3.0 \\
\hline
\end{tabular}


Table 3. Physician Delay (in Minutes) at Different Specialty Clinics Minutes in the Studied Center

\begin{tabular}{lccc}
\hline Specialty Clinic & Mean & Standard Deviation & Median \\
\hline Ear, nose, and throat & 101.6 & 40.7 & 120.0 \\
Orthopedic & 51.4 & 29.1 & 30.0 \\
Urology & 58.2 & 44.1 & 55.0 \\
\hline Psychology & 104.9 & 54.1 & 120.0 \\
\hline Anesthesia & 42.6 & 46.5 & 30.0 \\
Dermatology & 88.9 & 41.0 & 90.0 \\
\hline Surgery & 74.4 & 36.6 & 90.0 \\
\hline Ophthalmology & 45.9 & 39.7 & 50.0 \\
\hline Cardiovascular & 33.8 & 27.4 & 30.0 \\
\hline Internal disease & 14.2 & 24.9 & 20.0 \\
\hline Infectious disease & -2.6 & 20.8 & 0.0 \\
\hline Obstetrics and gynecology & 80.4 & 32.6 & 30.0 \\
\hline Neurosurgery & 80.4 & 29.3 & 80.0 \\
\hline Neurology & 77.9 & 49.9 & 60.0 \\
\hline Total & 59.4 & 49.6 & 60.0 \\
\hline
\end{tabular}

a $P$ value $<0.001$

The assessment of service time also indicated that nearly $60 \%$ of total service time was spent for examination rooms and clinics. Clearly, more than half of the total service time is spent for the main service in this process. This indicated that the administrative processes were logically designed and did not overwhelm the time of the main service. ${ }^{8}$ The median length of visits by specialists was estimated to be 3 minutes, which is low. Hasanpoor et al estimated specialist visit times in general hospitals in Qazvin and reported that the mean outpatient visit length was $4.67 \pm 2.43$ minutes, which is significantly different from the standard. ${ }^{28}$ TaiSeale et al showed that the median visit length was 15.7 minutes to visit primary care physicians in primary care practices in the United States. ${ }^{29}$ Evidence indicates that shortness of visit time is not a problem only for the studied center; it is a widespread problem throughout the country. Length of visit time and time spent on direct patient contact during the outpatient visit are associated with quality of care and patients' and physicians' satisfaction. Thus, efforts should be made to improve these criteria in the studied center. ${ }^{30}$

To reduce wait times, clinics with longer wait times should first be identified. In this study, the ear, nose, and throat; surgery; and neurosurgery clinics had the highest wait times. These clinics should be considered as the first priority for managerial intervention. Assessing the disciplines of these first priority clinics will help reduce wait times in these clinics and, consequently, in the hospital. ${ }^{31}$

One of the most important disciplines investigated in this study was physician delay. The results indicated that physician delay times positively affect patient wait time and should be considered as a key factor in designing managerial interventions. ${ }^{32}$

Considering the ratio of physicians to patients in these first priority clinics and simulating the performance of
Research Highlights

\section{What Is Already Known?}

There are different technics for reducing waiting time in healthcare facilities. PFA is one of them that is easier and more relevant. Considering the healthcare resources limitation reveals the necessity of using this technic in improving the productivity of resources.

\section{What This Study Adds?}

As the study showed, the use of the PFA plays an important role in depicting the work flow in health facilities, bottlenecks and ways to improve work flow. This method can be combined with simulation analysis or use solely. In our health system which using these decision making tools are not common, simplifying decision making tools will increase the application of these methods and will improve the health centers outputs and outcomes.

them could be helpful in measuring the impact of different strategies on patient wait time in the clinics. ${ }^{33,34}$

Analyzing patient flow was very helpful in defining the strengths and weaknesses of the studied hospital. Attention paid to the strengths and to eliminating the weaknesses will play an important role in increasing resource efficiency and improving patient satisfaction.

\section{Conclusion}

The studied center encountered 2 considerable challenges: relatively long wait times and short visit times. These two challenges are limiting factors that could affect patient satisfaction and quality of services. Managerial actions and techniques would be very effective in controlling the situation.

PFA is an effective technique for identifying healthcare processes that do not work well and need to improve. It is also useful in decreasing patient wait times for receiving care. In the current study, the use of PFA provided a good picture of the whole system. It also had some indirect impacts, including improved understanding by the clinic staff about the patient flow process and its bottlenecks. Most providers were surprised by the study results. It is hoped that this understanding will be effective on their behavior and performance in reducing the problems.

Different decision-making techniques can be used alone or along with PFA to provide evidence-based decisions. None were used in this study, considering the study objectives and time and money constraints.

Although the impact of implementing the interventions on system performance was not assessed in this study, related studies have indicated that improving patient flow will be effective in improving quality of services and patients' and providers' satisfaction.

\section{Authors' Contributions}

AA made substantial contributions to the study design, 
analysis, interpretation of data, and in drafting the manuscript. FF contributed to the study design and reviewing the manuscript. FM contributed to designing the study, interpreting the data, and drafting the manuscript. HY participated in the acquisition of data and gave final approval of the version to be published.

\section{Conflict of Interest Disclosures}

The authors declare that they have no conflicts of interest.

\section{Ethical Approval}

This study was assessed and approved in the hospital ethic committee.

\section{Acknowledgments}

This article is based on the "Patient flow analysis and assessing the wait time in hospital clinics" research project. This study was funded by contract no. 10100128 on 14th Nov. 2012 and planned and implemented by the Iranian Institute for Health Sciences Research (IHSR). The authors would like to thank everyone who contributed in this study.

\section{References}

1. Hall R, Belson D, Murali P, Dessouky M. Patient Flow: Reducing Delay in Healthcare Delivery. Springer US; 2013. doi:10.1007/978-1-4614-9512-3.

2. Dixon CA, Punguyire D, Mahabee-Gittens $M$, Ho M, Lindsell CJ. Patient flow analysis in resource-limited settings: a practical tutorial and case study. Glob Health Sci Pract. 2015;3(1):126134. doi:10.9745/ghsp-d-14-00121.

3. Bernstein SL, Aronsky D, Duseja R, et al. The effect of emergency department crowding on clinically oriented outcomes. Acad Emerg Med. 2009;16(1):1-10. doi:10.1111/ j.1553-2712.2008.00295.x.

4. Preyde M, Crawford K, Mullins L. Patients' satisfaction and wait times at Guelph General Hospital Emergency Department before and after implementation of a process improvement project. CJEM. 2012;14(3):157-168. doi:10.2310/8000.2012.110590.

5. Harnett MJ, Correll DJ, Hurwitz S, Bader AM, Hepner DL. Improving efficiency and patient satisfaction in a tertiary teaching hospital preoperative clinic. Anesthesiology. 2010;112(1):66-72. doi:10.1097/ALN.0b013e3181c617cb.

6. Aeenparast A, Maftoon F, Farzadi F, Mohamadi A. Waiting time for first outpatient visit in specialty level: assessing the provider related factors. Arch Iran Med. 2015;18(3):185-188.

7. Bard JF, Shu Z, Morrice DJ, Wang DE, Poursani R, Leykum L. Improving patient flow at a family health clinic. Health Care Manag Sci. 2016;19(2):170-191. doi:10.1007/s10729-0149294-y.

8. Mohebbifar R, Hasanpoor E, Mohseni M, Sokhanvar M, Khosravizadeh O, Mousavi Isfahani H. Outpatient waiting time in health services and teaching hospitals: a case study in Iran. Glob J Health Sci. 2013;6(1):172-180. doi:10.5539/gjhs. v6n1p172.

9. Mardiah FP, Basri MH. The Analysis of Appointment System to Reduce Outpatient Waiting Time at Indonesia's Public Hospital. Hum Resour Manag Res. 2013;3(1):27-33.

10. Armony $M$, Israelit $S$, Mandelbaum A, Marmor $Y N$, Tseytlin Y, Yom-Tov GB. On patient flow in hospitals: a data-based queueing-science perspective. Stoch Syst. 2015;5(1):146-194. doi:10.1287/14-ssy153.

11. Abuhay TM, Krikunov AV, Bolgova EV, Ratova LG, Kovalchuk SV. Simulation of Patient Flow and Load of Departments in a Specialized Medical Center. Procedia Comput Sci. 2016;101:143-151. doi:10.1016/j.procs.2016.11.018.

12. Rojas E, Munoz-Gama J, Sepúlveda M, Capurro D. Process mining in healthcare: a literature review. J Biomed Inform. 2016;61:224-236. doi:10.1016/j.jbi.2016.04.007.

13. Miró O, Sánchez M, Espinosa G, Coll-Vinent B, Bragulat E, Millá J. Analysis of patient flow in the emergency department and the effect of an extensive reorganisation. Emerg Med J. 2003;20(2):143-148; discussion 148. doi:10.1136/ emj.20.2.143.

14. Potisek NM, Malone RM, Shilliday BB, et al. Use of patient flow analysis to improve patient visit efficiency by decreasing wait time in a primary care-based disease management programs for anticoagulation and chronic pain: a quality improvement study. BMC Health Serv Res. 2007;7:8. doi:10.1186/14726963-7-8.

15. Thi Thao Nguyen $S$, Yamamoto $E$, Thi Ngoc Nguyen $M$, et al. Waiting time in the outpatient clinic at a national hospital in Vietnam. Nagoya J Med Sci. 2018;80(2):227-239. doi:10.18999/nagjms.80.2.227.

16. Almeida R, Paterson WG, Craig N, Hookey L. A patient flow analysis: identification of process inefficiencies and workflow metrics at an ambulatory endoscopy unit. Can J Gastroenterol Hepatol. 2016;2016:2574076. doi:10.1155/2016/2574076.

17. Olwanda E, Shen J, Kahn JG, Bryant-Comstock K, Huchko MJ. Comparison of patient flow and provider efficiency of two delivery strategies for HPV-based cervical cancer screening in Western Kenya: a time and motion study. Glob Health Action. 2018;11(1):1451455. doi:10.1080/16549716.2018.1451455.

18. Khatibi T, Nejadjafari N. Extraction and comparison of the discharge process in a teaching hospital. In J Hosp Res. 2017;6(1):19-29.

19. Liang B, Turkcan A, Ceyhan ME, Stuart K. Improvement of chemotherapy patient flow and scheduling in an outpatient oncology clinic. Int J Prod Res. 2015;53(24):7177-7190. doi:1 0.1080/00207543.2014.988891.

20. Savage DW, Woolford DG, Weaver B, Wood D. Developing emergency department physician shift schedules optimized to meet patient demand. Cjem. 2015;17(1):3-12. doi:10.2310/8000.2013.131224.

21. Palmer R, Fulop NJ, Utley M. A systematic literature review of operational research methods for modelling patient flow and outcomes within community healthcare and other settings. Health Syst (Basingstoke). 2018;7(1):29-50. doi:10.1057/ s41306-017-0024-9.

22. Rezai S, Chicarilli DM, Hardy K, et al. Use of patient flow analysis to improve patient access and clinical efficiency by decreasing patient wait time in a tertiary community hospital Ob/Gyn ambulatory women's clinic: a quality improvement (QI) projectst century. Obstet Gynecol Int J. 2015;3(1):248253. doi:10.15406/ogij.2015.03.00071.

23. Zhao L, Lie B. Modeling and Simulation of Patient Flow in Hospitals for Resource Utilization. Simulation Notes Europe. 2010;20(2):41-50. doi:10.11128/sne.20.tn.09976.

24. Koo PH, Nielsen KB, Jang J, Kolker A, Simulation-based patient flow analysis in an endoscopy unit. In: 2010 IEEE Workshop on Health Care Management (WHCM); 18-20 Feb. 20102010 : Venice, Italy. doi:10.1109/WHCM.2010.5441266.

25. Aeenparast A, Pour Reza A. Assessing outpatient's waiting time and its related factor. Journal of Hospital. 1999;1:21-26. [Persian].

26. Bahadori $M$, Teymourzadeh E, Ravangard $R$, Raadabadi $M$. Factors affecting the overcrowding in outpatient healthcare. J Educ Health Promot. 2017;6:21. doi:10.4103/22779531.204742.

27. Pandit A, Varma L, Pandit A. Impact of OPD waiting time on patient satisfaction. Int Educ Res J. 2016;2(8):86-90. 
28. Hasanpoor E, Delgoshaie B, Abolghasem Gorji H, Khoshkam $M$, Jannati A, Sokhanvar M. Surveying the standard of outpatient visit time among general hospitals: a case study in Qazvin. Journal of Hospital. 2015;14(3):75-81. [Persian].

29. Tai-Seale M, McGuire TG, Zhang W. Time allocation in primary care office visits. Health Serv Res. 2007;42(5):1871-1894. doi:10.1111/j.1475-6773.2006.00689.x.

30. Smeulers $M$, Dikmans $M$, van Vugt $M$. Well-prepared outpatient visits satisfy patient and physican. BMJ Open Qual. 2019;8(3):e000496. doi:10.1136/bmjoq-2018-000496.

31. Johannessen KA, Alexandersen N. Improving accessibility for outpatients in specialist clinics: reducing long waiting times and waiting lists with a simple analytic approach. BMC Health Serv Res. 2018;18(1):827. doi:10.1186/s12913-018-3635-3.
32. Hoseini B. Appointment planning and scheduling in primary care [dissertation]. Newark, NJ: Faculty of New Jersey Institute of Technology, Department of Mechanical and Industrial Engineering; 2017.

33. Granja C, Almada-Lobo B, Janela F, Seabra J, Mendes A. An optimization based on simulation approach to the patient admission scheduling problem using a linear programing algorithm. J Biomed Inform. 2014;52:427-437. doi:10.1016/j. jbi.2014.08.007.

34. Luo L, Zhou Y, Han BT, et al. A simulation model for outpatient appointment scheduling with patient unpunctuality. International Journal of Simulation and Process Modelling. 2016;11(3-4):281-291. 